\title{
Genetic Parameters for Health Traits and Their Relationship to Different Persistency Traits in German Holstein Dairy Cattle
}

\author{
B. Harder, J. Bennewitz, ${ }^{1}$ D. Hinrichs, and E. Kalm \\ Institut für Tierzucht und Tierhaltung der Christian-Albrechts-Universität zu Kiel, D-24098 Kiel, Germany
}

\begin{abstract}
Data from 3,200 Holstein cows from 3 commercial dairy farms in Germany were used to estimate heritabilities and breeding values for liability to udder diseases (UD), fertility diseases (FD), metabolic diseases (MD), and claw and leg diseases (CLD) using singletrait threshold sire models. A total of 92,722 medical treatments recorded from 1998 to 2003 were included in the analysis. Approximate genetic correlations between persistency of milk yield, fat yield, protein yield, and persistency of milk energy yield and liability to the health traits were calculated based on correlations between EBV. Posterior means of heritability of liability ranged from 0.05 to 0.08 for UD, from 0.04 to 0.07 for $\mathrm{FD}$, from 0.08 to 0.12 for $\mathrm{MD}$, and from 0.04 to 0.07 for CLD. Approximate genetic correlations of the disease traits with the persistency traits were favorable, except for MD in all lactations, which were unfavorable, and UD, which were around zero. Highest correlations in the range of 0.13 to 0.46 were found between the different persistency traits and CLD.
\end{abstract}

Key words: dairy cattle, disease liability, persistency

\section{INTRODUCTION}

During recent decades, selection in dairy cattle has mainly focused on milk production traits, whereas socalled functional traits such as health, fertility, calving ease, efficiency of feed use, or milkability have been of minor interest. However, due to unfavorable genetic correlations between production traits and liability to various diseases (e.g., Lyons et al., 1991), the intensive selection for increased milk production is expected to result in a genetic deterioration of resistance to the diseases and increased risk of culling due to diseases and other disorders, which causes a considerable financial loss in commercial milk production. Therefore, the interest in genetic improvement of health traits has increased in recent years.

Received April 26, 2005.

Accepted February 1, 2006.

${ }^{1}$ Corresponding author: jbennewitz@tierzucht.uni-kiel.de
The definition of the breeding goal for organic dairy cattle breeding as well as for the Scandinavian countries has changed to include more emphasis on functional traits. For breeding cattle for organic milk production, this is mainly due to ethical issues with regard to animal welfare. The breeding goal in organic dairy cattle breeding for Simmental, Brown Swiss, and Yellow Cattle in Germany includes persistency (Krogmeier, 2003). Persistency is defined as the ability of a cow to maintain milk production at a high level after the peak yield (Jamrozik et al., 1998). The hypothesis that good persistency leads to fewer health problems can be explained as follows: A cow with a flatter lactation curve is more persistent than a cow with the same total milk yield but with a curve that decreases rapidly after peak yield (Grossman et al., 1999). The lower peak yield at the beginning of the lactation causes less energy imbalance, and consequently, the cows mobilize less body reserves to meet the increased nutrient demand for milk production (Tamminga, 2000). Thus, metabolic stress is reduced. Metabolic stress may explain why most health problems occur at the beginning of the lactation; that is, between calving and peak yield. Following this, cows with good persistency may have fewer reproductive and health problems than cows with the same total milk yield that are less persistent. In contrast to the disease traits (in which a routine data collection system is rarely implemented and thus, reliable breeding values are difficult to obtain), breeding values for the persistency traits are by-products of the application of random regression models in routine sire evaluations. Thus, including persistency in the breeding goal could help to improve the disease traits if genetic correlations are favorable and sufficiently strong. In addition, it is sometimes argued that a cow with high persistency incurs lower feed, health, and reproduction costs, and therefore is more profitable (Dekkers et al., 1998).

Investigations of relationships between persistency and different health traits are rare. Muir et al. (2004) estimated genetic correlations of different fertility traits with persistency of milk yield to be from -0.09 to 0.23 . Haile-Mariam et al. (2003) found an unfavorable genetic correlation between somatic cell count and persistency of milk yield of -0.05 . This unfavorable correla- 
Table 1. Number of observations (n), mean lactation length (MLL) and standard deviation (SD), and frequencies for udder diseases (UD), fertility diseases (FD), metabolic diseases (MD), and claw and leg diseases (CLD) in different lactations

\begin{tabular}{llllllrl}
\hline Lactation no. & $\mathrm{n}$ & $\begin{array}{l}\text { MLL } \\
(\mathrm{d})\end{array}$ & $\mathrm{SD}$ & $\begin{array}{l}\mathrm{UD} \\
(\%)\end{array}$ & $\begin{array}{l}\text { FD } \\
(\%)\end{array}$ & $\begin{array}{l}\text { MD } \\
(\%)\end{array}$ & $\begin{array}{l}\text { CLD } \\
(\%)\end{array}$ \\
\hline 1 & 8,291 & 141 & 87 & 38.7 & 50.9 & 7.5 & 11.4 \\
2 & 4,953 & 140 & 86 & 44.5 & 49.0 & 10.0 & 12.4 \\
3 & 3,141 & 138 & 86 & 48.5 & 47.8 & 18.6 & 14.6 \\
$>3$ & 2,916 & 135 & 86 & 48.9 & 49.0 & 25.8 & 14.2 \\
\hline
\end{tabular}

tion between health traits and persistency was confirmed by Jakobsen et al. (2003). These authors found unfavorable genetic correlations between persistency and disease liability at different stages of lactation.

The aim of this study was to estimate variance components and breeding values for four health traits, udder diseases (UD), metabolic diseases (MD), fertility diseases (FD), and claw and leg diseases (CLD). In addition, genetic correlations between different persistency traits and liability to UD, MD, FD, and CLD were approximated from correlations between EBV. Analyses were carried out for German Holstein-Friesian dairy cattle using data from the first lactation and from multiple lactations, separately.

\section{MATERIALS AND METHODS}

\section{Data}

Data were recorded on 3 large commercial dairy farms with a total of 3,200 German Holstein cows. The farms were involved in a project to develop a new datarecording scheme, with special focus on recording of health data. Data were collected from February 1998 to December 2003. The lactation period considered began with the calving date and ended at $300 \mathrm{~d}$ of lactation. Two data sets were formed; one included first-lactation cows only, and the second included all lactations. The first 3 lactations were treated as separate classes, whereas lactation $>3$ were grouped into one class. The first data set consisted of 8,291 daughters of 101 sires, and the second set consisted of 9,303 daughters of 142 sires. The sire pedigree file had 1,109 males. Summary statistics of the 2 data sets are in Table 1.

Medical treatments were performed and recorded by veterinarians or farm staff. Questionable treatments were discarded. The treatments were divided into the 5 different disease categories UD, FD, MD, CLD, and other diseases. Of the 92,722 treatments available for the analysis, there were incidents of 49,484 UD, 31,749 FD, 4,970 MD, 6,191 CLD, and 328 other diseases. Of all treated UD, $95 \%$ were cases of mastitis. The category FD included ovarian disorders, endometritis, retained placenta, and other fertility diseases, whereas MD in- cluded displaced abomasum, ketosis, diarrhea, milk fever, and other metabolic diseases. The category CLD included interdigital necrobacteriosis, interdigital dermatitis, laminitis, sole ulcer, digital dermatitis, and other claw and leg diseases. The different disease categories, except for the disease category "other diseases," which was not evaluated, were analyzed separately. The diseases were grouped into disease categories to lower the potential sources of error, because different diagnoses might describe the same disease. All diseases were defined as binary data $(0=$ no disease, $1=$ disease $)$, based on whether a cow had at least one recorded incident of that disease. Cows that were culled before the end of lactation were also scored, irrespective of the number of completed days. Frequencies of the different disease categories for the 2 data sets are in Table 1 , which shows that FD were the most frequent diseases in all lactations, followed by UD. For all diseases except $\mathrm{FD}$, the disease frequencies were higher in later lactations.

More than $30 \%$ of all cows had more than one case of FD per lactation. More than one case of UD was observed for $14 \%$ of the cows in the first lactation period and $18 \%$ of the cows in all lactations. In contrast, for MD and CLD, less than 3\% of the cows had repeated medical treatments in the same lactation. Therefore, due to repeated observations, FD and UD were analyzed with one observation per lactation, and additionally by dividing the lactation into blocks. For each cow, lactation, and disease category, the period ranging from calving to $300 \mathrm{~d}$ of lactation was divided into 6 blocks of $50 \mathrm{~d}$ each. Within each block, absence or presence of the considered disease was scored as 0 or 1 . The sequence of the respective disease was viewed as repeated measurements of the same trait throughout lactation. Cows that were culled before the end of lactation were also scored in the block in which they were culled, irrespective of the number of completed days in that last block. For this analysis, lactations 4 and later were excluded. In the first lactation, the data for the block model therefore included 8,474 daughters of 374 sires, and the all-lactation data had 10,196 daughters of 547 sires. Frequencies of FD and UD by block and lactation 
Table 2. Frequencies (\%) of fertility diseases (FD) and udder diseases (UD) in the six 50-d blocks of lactations 1 to $3^{1}$

\begin{tabular}{|c|c|c|c|c|c|c|c|}
\hline \multirow[b]{2}{*}{ Period } & \multirow{2}{*}{$\begin{array}{l}\text { Days after } \\
\text { calving }\end{array}$} & \multicolumn{2}{|c|}{ Lactation 1} & \multicolumn{2}{|c|}{ Lactation 2} & \multicolumn{2}{|c|}{ Lactation 3} \\
\hline & & FD & UD & FD & UD & FD & UD \\
\hline 1 & 1 to 50 & 43.2 & 28.9 & 35.7 & 24.5 & 34.9 & 27.0 \\
\hline 2 & 51 to 100 & 16.8 & 7.8 & 17.3 & 14.2 & 18.1 & 16.4 \\
\hline 3 & 101 to 150 & 14.7 & 6.5 & 15.9 & 12.6 & 17.0 & 15.2 \\
\hline 4 & 151 to 200 & 5.7 & 6.4 & 5.7 & 11.6 & 6.0 & 13.4 \\
\hline 5 & 201 to 250 & 0.7 & 6.2 & 0.6 & 9.3 & 0.5 & 10.7 \\
\hline 6 & 251 to 300 & 0.2 & 6.1 & 0.1 & 8.2 & 0.1 & 9.1 \\
\hline
\end{tabular}

${ }^{1}$ For each cow, lactation, and disease category, the period ranging from calving to $300 \mathrm{~d}$ of lactation was divided into 6 blocks of $50 \mathrm{~d}$ each. Within each block, absence or presence of the considered disease was scored as 0 or 1 , respectively.

are in Table 2. Herd-year-season of calving had 54 levels formed from 3 herds, 6 years, and 3 seasons (JanuaryMarch, April-August, and September-December).

\section{Variance Components for Health Traits}

The binary data of the 4 disease categories were analyzed for all lactations and for first lactation only. The following single-trait threshold sire model (Gianola, 1982; Gianola and Foulley, 1983) subsequently referred to as the lactation model, was applied for the analyses:

$$
E\left[\pi_{i j k l}\right]=\Phi\left(K_{i}+L_{j}+c_{1} x+c_{2} x^{2}+v_{l}+u_{m}\right),
$$

where $E\left[\pi_{\mathrm{ijkl}}\right]$ is the expected percentage of animals with the respective disease, $\Phi$ is the cumulative probability function of the standard normal distribution, $\mathrm{K}_{\mathrm{i}}$ is the effect of the ith herd-year-season, $L_{j}$ is the effect of the jth lactation, $c_{1} x$ is the linear regression on the $x$ th DIM, and $c_{2} x^{2}$ is the quadratic regression on the xth DIM, both accounting for the case that cows leave production before 300 DIM, $\mathrm{v}_{1}$ is the random permanent environmental effect of the lth cow, and $u_{m}$ is the random effect of the mth sire. The model applied for the analysis of the first-lactation data was equivalent but without the effects of lactation and permanent environment.

The second sire model used for all lactations, subsequently denoted as the block model, was:

$$
E\left[\pi_{i j k l m}\right]=\Phi\left(K_{i}+L_{j}+B_{k}+c_{1} p+c_{2} p^{2}+v_{l}+u_{m}\right),
$$

where $B_{k}$ is the effect of the kth block, $c_{1} p$ is the linear regression on the pth day in milk in the kth block and $c_{1} p^{2}$ is the quadratic regression on the pth day in milk in the kth block, both accounting for the case that cows leave production before the end of the respective period, and the remaining terms are the same as defined in [1]. The model applied for the analysis of the first-lactation data excluded the effect of lactation.
Equations [1] and [2] show that the all-lactation data set and the block model data sets were analyzed using repeatability models (single trait threshold). The repeatability model assumes that the respective disease category in question is the same trait in all lactations and lactation periods.

In the Bayesian analysis the posterior distributions of the permanent environmental variance and the sire variance for the liability to the different disease classes were determined through the Gibbs sampling algorithm implemented in the LMMG_TH program, a threshold derivative of LMMG (Reinsch, 1996). In the threshold model, an unobservable normally distributed variable (liability) is assumed for each observation. If the liability value exceeds a fixed threshold, the respective binary variable disease takes value 1 , otherwise disease $=0$. The liability values were created by data augmentation, as described by Sorensen et al. (1995), drawing random variables from truncated normal distributions, which are conditional upon the other fixed and random effects in the model.

Improper uniform priors were assumed for all effects in the model, except for the sire effects and the permanent environmental effects. For these, normality was assumed. The ith fixed effect $\beta_{\mathrm{i}}$ was sampled from

$$
\beta_{\mathrm{i}} \sim \mathrm{N}\left(\mathbf{x}_{\mathbf{i}}^{\prime} \mathbf{Y}^{*} \times \mathrm{dxx}_{\mathrm{i}}^{-1}, \sigma_{\mathrm{e}}^{2} \times \mathrm{dxx}_{\mathrm{i}}^{-1}\right),
$$

where $\beta$ is a $\mathrm{f} \times 1$ vector of fixed effects with $\beta_{\mathrm{i}}$ being the ith component of $\beta$ and $f$ being the number of levels for all fixed effects, $\mathbf{x}_{\mathbf{i}}$ is the ith column vector extracted from the design matrix $\mathbf{X}, \mathbf{x}_{\mathbf{i}}^{\prime} \mathbf{Y}^{*}$ is the sum of corrected observations pertaining to the ith level of $\beta, \mathbf{Y}$ is an $\mathrm{m}$ $\times 1$ data vector with $\mathrm{m}$ being the number of observations, $\mathbf{Y}^{*}$ is $\mathbf{Y}$ corrected for all fixed and random effects except the ith component of $\beta$, and $\mathrm{dxx}_{\mathrm{i}}$ is the ith diagonal element of $\mathbf{X}^{\prime} \mathbf{X}$.

With binary data, the threshold and the residual variance are not identifiable; therefore, these parameters were set to 0 and 1 , respectively. 
The ith permanent environmental effect $v_{i}$ was sampled from

$$
\mathrm{v}_{\mathrm{i}} \sim \mathrm{N}\left(\mathbf{w}_{\mathrm{i}}^{\prime} \mathbf{Y}^{* *} \times \mathrm{dww}_{\mathrm{i}}^{-1}, \sigma_{\mathrm{e}}^{2} \times \mathrm{dww}_{\mathrm{i}}^{-1}\right),
$$

where $\mathbf{v}$ is a $g \times 1$ vector of permanent environment effects with $\mathrm{v}_{\mathrm{i}}$ being the ith component of $\mathbf{v}$ and $\mathbf{g}$ being the number of permanent environmental effects, $\mathbf{w}_{\mathbf{i}}$ is the ith column vector extracted from the design matrix $\mathbf{W}, \mathbf{w}_{\mathbf{i}}^{\prime} \mathbf{Y}^{* *}$ is the sum of corrected observations pertaining to the ith level of $\mathbf{v}, \mathbf{Y}^{* *}$ is $\mathbf{Y}$ corrected for all fixed and random effects except the ith component of $\mathbf{v}$, and $d w_{w}$ is the ith diagonal element of $\mathbf{W}^{\prime} \mathbf{W}+\mathbf{I} \alpha_{1}$, with $\mathbf{I}$ being an identity matrix and $\alpha_{1}=\sigma_{\mathrm{e}}^{2} / \sigma_{\mathrm{pe}}^{2}$ with $\sigma_{\text {pe }}^{2}$ being the permanent environmental variance.

The ith sire effect $u_{i}$ was sampled from

$$
\mathrm{u}_{\mathrm{i}} \sim \mathrm{N}\left(\mathbf{z}_{\mathbf{i}}^{\prime} \mathbf{Y}^{* * *} \times \mathrm{dzz}_{\mathrm{i}}^{-1}, \sigma_{\mathrm{e}}^{2} \times \mathrm{dzz}_{\mathrm{i}}^{-1}\right),
$$

where $\mathbf{u}$ is a $h \times 1$ vector of sire effects with $u_{i}$ being the ith component of $\mathbf{u}$ and $\mathrm{h}$ being the number of sire effects, $\mathbf{Y}^{* * *}$ is $\mathbf{Y}$ corrected for all fixed and random effects except the ith random sire effect, $\mathbf{z}_{\mathbf{i}}$ is the ith column vector extracted from the design matrix $\mathbf{Z}$, $\mathbf{z}_{\mathbf{i}}^{\prime} \mathbf{Y}^{* * *}$ is the sum of corrected observations pertaining to the ith level of $\mathbf{u}, \mathrm{dzz}_{\mathrm{i}}$ is the ith diagonal element of the matrix $\mathbf{Z}^{\prime} \mathbf{Z}+\mathbf{A}^{-1} \alpha_{2}$ and $\alpha_{2}=\sigma_{\mathrm{e}}^{2} / \sigma_{\mathrm{a}}^{2}, \sigma_{\mathrm{a}}^{2}$ being the additive genetic variance and $\mathbf{A}$ being the numerator relationship matrix.

The $\sigma_{\mathrm{pe}}^{2}$ was sampled from an inverted $\chi^{2}$-distribution with $g-2$ degrees of freedom. The inverted $\chi^{2}$-distribution was scaled by $\mathbf{v}^{\prime} \mathbf{v}$. The $\sigma_{\mathrm{a}}^{2}$ was sampled from an inverted $\chi^{2}$-distribution with $\mathrm{h}-2$ degrees of freedom. The inverted $\chi^{2}$-distribution was scaled by $\mathbf{u}^{\prime} \mathbf{A}^{-1} \mathbf{u}$.

According to Geyer (1992), the Gibbs sampler was run in a single, long-chain scheme. For all models the sampler ran 120,000 rounds. The results from each round were retained. Convergence was determined by visual inspection of the trace plots. The first 20,000 iterations were discarded (burn-in plus safety margin), and the results of the remaining 100,000 iterations were used to obtain posterior distributions of the variance components.

\section{Estimation of Sire Posterior Means For Health Traits}

To obtain posterior means of sire breeding values the variance components were fixed and the other parameters were sampled as described above (Eq. [3], [4], and [5]). The first-lactation data and the all-lactation data were again analyzed separately.

The convergence of the Gibbs chain was controlled by visual inspection of the trace plots. For this purpose the posterior distributions of the breeding values of 10 sires with different amounts of relationship information were examined. After the inspection, the same length was chosen for the Gibbs chain and the burn-in period as for the estimation of the variance components. The sire posterior mean (SPM) based on 100,000 samples were transformed to the probability scale ( 0 to 1) using

$$
p_{i j}=\Phi\left(\mu_{i}+S P M_{i j}\right)
$$

where $p_{i j}$ is the probability of disease $i$ for daughters of sire $j, \mu$ is the probit function corresponding to the mean liability of disease $\mathrm{i}$, and $\mathrm{SPM}_{\mathrm{ij}}$ is the posterior mean of liability to the different diseases $i$ of sire $j$.

Then, to calculate breeding values corresponding to the EBV for persistency, the SPM was multiplied by 2 because of the sire model, and by -1 so that the sires with the lowest incidence of disease would have the highest breeding values. For the estimation of the breeding values, only those sires with more than 20 daughters were considered. The reliabilities for the breeding values $\left(R_{\mathrm{i}}\right)$ were estimated by

$$
\mathrm{R}_{\mathrm{i}}=\frac{\sigma_{\mathrm{s}}^{2}-\mathrm{PEV}_{\mathrm{i}}}{\sigma_{\mathrm{s}}^{2}}
$$

where $\mathrm{PEV}_{\mathrm{i}}$ is the predicted error variance of sire $\mathrm{i}$, which was approximated by the variance of the estimated sire effect from the 100,000 iterations, and $\sigma_{\mathrm{s}}^{2}$ is the posterior mean of the sire variance obtained from the variance component estimation.

\section{Persistency}

For the estimation of breeding values for persistency of milk yield (PMY), persistency of fat yield (PFY), and persistency of protein yield (PPY), the Vereinigte Informationssysteme Tierhaltung (VIT) provided random regression coefficients for the sires obtained from the German Holstein genetic evaluation. Breeding values of the first 3 lactations are routinely estimated with a random regression animal model using test-day records (for further information see www.vit.de). To derive (co)variances of the random regression coefficients for the first 3 lactations, third-order, normalized orthogonal Legendre polynomials were chosen. Breeding values for milk, fat, and protein yield for sire i, lactation $\mathrm{j}$, and time $\mathrm{t}$ were calculated according to Liu et al. (2000) as

$$
\operatorname{EBV}_{\mathrm{ijt}}=\mathrm{a}_{1 \mathrm{ij}}+\mathrm{a}_{2 \mathrm{ij}} \sqrt{3} \mathrm{q}_{\mathrm{t}}+\mathrm{a}_{3 \mathrm{ij}} \frac{\sqrt{5}}{2}\left(3 q_{\mathrm{t}}^{2}-1\right),
$$


where $a_{1}, a_{2}$, and $a_{3}$ represent the random regression coefficients, and $\mathrm{q}_{\mathrm{t}}$ is the standardized day at time $\mathrm{t}$, with values ranging from -1 to 1 (Kirkpatrick et al., 1990). The standardized day $q_{t}$ was computed as

$$
\mathrm{q}_{\mathrm{t}}=-1+\frac{2}{\mathrm{t}_{\max }-\mathrm{t}_{\min }}\left(\mathrm{t}-\mathrm{t}_{\min }\right)
$$

where $t_{\min }$ and $t_{\max }$ are the smallest and the largest values of time $\left(t_{\min }=d 5, t_{\max }=d 305\right)$.

Persistency of sire $\mathrm{i}$ for lactation $\mathrm{j}$ and trait $\mathrm{k}$ (milk, fat and protein yields) was calculated as (www.lfl. bayern.de)

$$
\begin{gathered}
\text { persistency }_{\mathrm{ijk}}=\sum_{\mathrm{d}=61}^{300} \mathrm{EBV}_{\mathrm{ijkd}} \\
-240 \times \mathrm{EBV}_{\mathrm{ijkd}=60} .
\end{gathered}
$$

The EBV for the different persistency traits were calculated for lactations 1 to 3 separately. The EBV that combined all 3 lactations were defined as the mean EBV of all 3 lactations. Reliabilities of the breeding values of the persistency traits were approximated by the reliabilities of the breeding values for milk yield.

For the prediction of breeding values for milk gross energy yield the following formula developed by Nostitz and Mielke (1995) was used:

$$
\begin{gathered}
\mathrm{EBV}_{\mathrm{E}_{\mathrm{ij}}=0 .}=0.2 \times \mathrm{EBV}_{\mathrm{M}_{\mathrm{ij}}}+38.4 \times \mathrm{EBV}_{\mathrm{F}_{\mathrm{ij}}} \\
+23.6 \times \mathrm{EBV}_{\mathrm{P}_{\mathrm{ij}}},
\end{gathered}
$$

where $\mathrm{EBV}_{\mathrm{E}_{\mathrm{ij}}}, \mathrm{EBV}_{\mathrm{M}_{\mathrm{ij}}}, \mathrm{EBV}_{\mathrm{F}_{\mathrm{ij}}}$, and $\mathrm{EBV}_{\mathrm{P}_{\mathrm{ij}}}$ are the breeding values of milk energy, milk, fat and protein yields on day $i$ of sire $j$, respectively.

\section{Approximate Genetic Correlations}

Pearson correlations were calculated between the respective EBV for the persistency traits and the disease traits. The comparison-wise error probabilities for the Pearson correlation coefficients were obtained from the $t$-distribution with $\mathrm{n}-2$ degrees of freedom. The estimation of 16 correlation coefficients between the 4 disease categories and the 4 persistency traits resulted in a multiple testing problem. Therefore, the estimated comparison-wise error probabilities were transformed into experiment-wise probabilities using the Bonferroni correction:

$$
\mathrm{P}_{\text {experiment-wise }}=1-\left(1-\mathrm{P}_{\text {comparison-wise }}\right)^{16} \text {. }
$$

The estimated correlation coefficients were used to approximate genetic correlations with the approach proposed by Calo et al. (1973):

$$
\mathrm{r}_{\mathrm{g} 1,2}=\frac{\sqrt{\left(\sum_{\mathrm{i}=1}^{\mathrm{n}} \mathrm{R}_{1 \mathrm{i}}\right) *\left(\sum_{\mathrm{i}=1}^{\mathrm{n}} \mathrm{R}_{2 \mathrm{i}}\right)}}{\left(\sum_{\mathrm{i}=1}^{\mathrm{n}} \mathrm{R}_{1 \mathrm{i}} * \mathrm{R}_{2 \mathrm{i}}\right)} * \mathrm{r}_{1,2},
$$

where $\mathrm{n}$ is the number of sires with observations, and $R_{1}$ and $R_{2}$ are the reliabilities of the EBV of persistency and disease traits, respectively, and $r_{1,2}$ is the Pearson correlation between the EBV.

\section{RESULTS}

\section{Heritabilities}

Posterior mean and standard deviation (SD) of sire variances, permanent environmental variances, and of heritability of liability to UD, FD, MD, and CLD for the 2 data sets are in Table 3. For the first lactation, MD showed the highest (0.12) heritabilities followed by UD (0.08) and FD and CLD (0.07). For the first 3 lactations, heritabilities for UD were identical to that estimated only for the first lactation, whereas the heritabilities of MD (0.08), FD (0.04), and CLD (0.04) were lower than when using first-lactation data only. Posterior means of permanent environmental variance were lowest for MD (0.07) and highest for UD (0.14). Posterior distributions of heritabilities for the different disease categories and both data sets inferred with the lactation model are shown in Figures 1 and 2. The figures illustrate almost symmetric distributions for all disease categories, except for the posterior distribution of CLD in the first lactation that tended to be skewed to the right. A comparison between data of the first lactation (Figure 1) and all lactations (Figure 2) shows that the posterior distribution of heritability of liability to all 4 disease categories were sharper when data from all lactations were used (Figure 2) than when based on first lactation only (Figure 1); this is most obvious for MD.

The results of the block model are shown in Table 3. Estimated heritabilities for both data sets were lower than for the lactation model, except for FD estimated in all lactations. Posterior means of permanent environmental variance were greater for the first lactation $(0.21$ to 0.25$)$ than for all lactations $(0.12$ to 0.19$)$. Posterior distributions of heritabilities for UD and FD estimated with the block model are given in Figure 3. The block model gave sharper distributions. The posterior standard deviations were 0.01 for all disease traits esti- 
Table 3. Mean and standard deviation (SD) of posterior distribution of sire variance, permanent environmental variance (PE), and heritability $\left(\mathrm{h}^{2}\right)$ of liability to udder diseases (UD), fertility diseases (FD), metabolic diseases (MD), and claw and leg diseases (CLD) ${ }^{1}$

\begin{tabular}{|c|c|c|c|c|c|c|}
\hline & $\begin{array}{l}\text { Sire } \\
\text { variance }\end{array}$ & $\begin{array}{l}\text { SD of } \\
\text { sire } \\
\text { posterior } \\
\text { distribution }\end{array}$ & $\begin{array}{l}\mathrm{PE} \\
\text { variance }\end{array}$ & $\begin{array}{l}\mathrm{SD} \text { of } \\
\mathrm{PE} \\
\text { posterior } \\
\text { distribution }\end{array}$ & $\mathrm{h}^{2}$ & $\begin{array}{l}\text { SD } \\
\text { of } h^{2}\end{array}$ \\
\hline \multicolumn{7}{|c|}{ Model 1 , data set 1} \\
\hline UD & 0.022 & 0.03 & - & - & 0.08 & 0.03 \\
\hline FD & 0.018 & 0.03 & - & - & 0.07 & 0.03 \\
\hline MD & 0.034 & 0.03 & - & - & 0.12 & 0.03 \\
\hline CLD & 0.018 & 0.04 & - & - & 0.07 & 0.04 \\
\hline \multicolumn{7}{|c|}{ Model 1 , data set 2} \\
\hline UD & 0.025 & 0.03 & 0.14 & 0.02 & 0.08 & 0.02 \\
\hline FD & 0.011 & 0.02 & 0.11 & 0.03 & 0.04 & 0.02 \\
\hline MD & 0.023 & 0.02 & 0.07 & 0.03 & 0.08 & 0.02 \\
\hline CLD & 0.012 & 0.02 & 0.13 & 0.03 & 0.04 & 0.02 \\
\hline \multicolumn{7}{|c|}{ Model 2 , data set 1} \\
\hline UD & 0.015 & 0.01 & 0.25 & 0.02 & 0.05 & 0.01 \\
\hline FD & 0.011 & 0.01 & 0.21 & 0.02 & 0.04 & 0.01 \\
\hline \multicolumn{7}{|c|}{ Model 2 , data set 2} \\
\hline UD & 0.018 & 0.01 & 0.19 & 0.009 & 0.06 & 0.01 \\
\hline FD & 0.011 & 0.01 & 0.12 & 0.009 & 0.04 & 0.01 \\
\hline
\end{tabular}

${ }^{1}$ Data for first lactation (data set 1 ) and for all lactations (data set 2) were estimated with the lactation model (model 1) and with the block model (model 2), where each lactation was divided into 50-d periods and disease was scored as present or absent in each period.

mated with the block model, whereas the SD estimated with the lactation model ranged between 0.02 and 0.06 .

\section{Breeding Values}

Mean SPM for daughters' liability to disease for the respective disease categories are in Table 4 . The mean SPM for the respective disease categories were in agreement with the disease frequencies shown in Tables 1 and 2. Compared with the lactation model, SPM for daughters' probability to disease were lower for the block model. This difference is caused by the fact that, in the block model, the daughters' probability to the

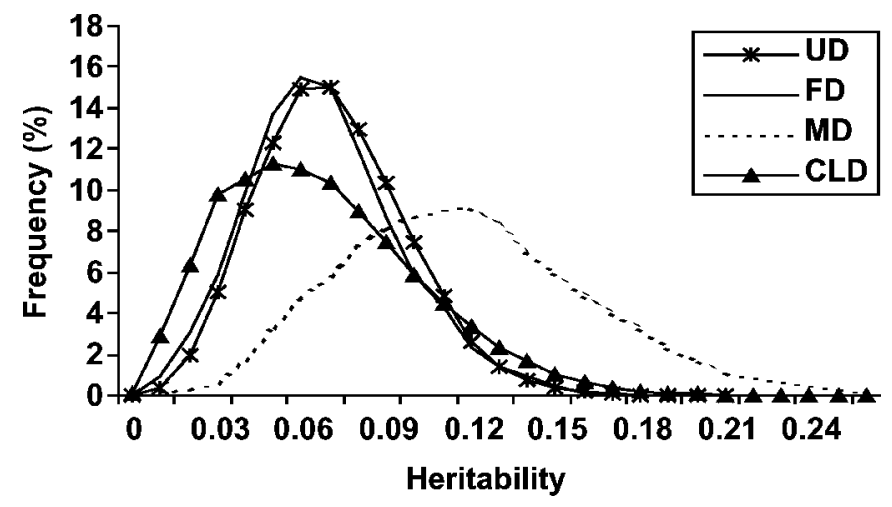

Figure 1. Posterior distributions of heritabilities of liability to udder diseases (UD), fertility diseases (FD), metabolic diseases (MD), and claw and leg diseases (CLD) for the first lactation estimated with the lactation model. respective disease is defined as the mean disease probability in all blocks. The difference between the best and the worst sires was most obviously for MD.

The amount of information for a sire, that is, number of daughters and pedigree information, influences the variance of the posterior samples. For example, the variance of the posterior samples of sire A (28 daughters) was 5 times as high as that of sire B (355 daughters; not shown).

The EBV for PMY ranged from -728 to 419 and from $-1,046$ to 434 for the first lactation and for all lactations, respectively. For PFY, the EBV for both data files varied from -28 to 21 and from -35 to 20 ; and for PPY, the

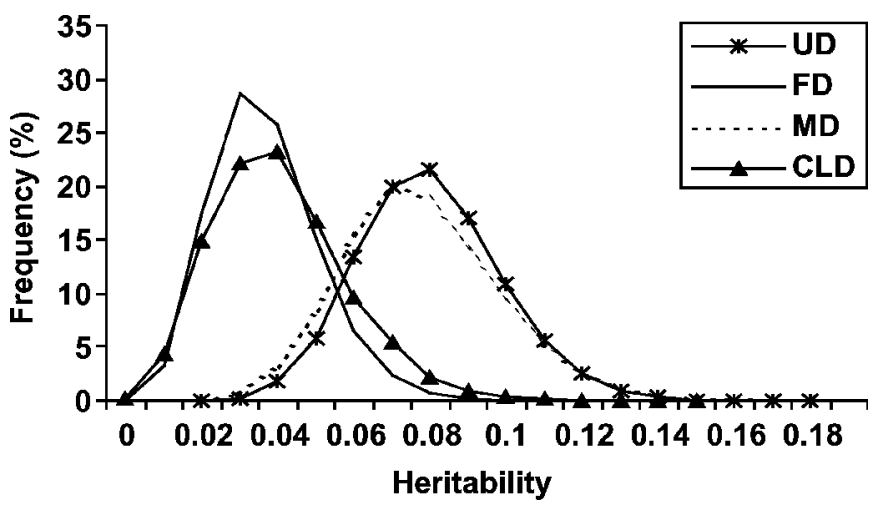

Figure 2. Posterior distributions of heritabilities of liability to udder diseases (UD), fertility diseases (FD), metabolic diseases (MD), and claw and leg diseases (CLD) for all lactations estimated with the lactation model. 


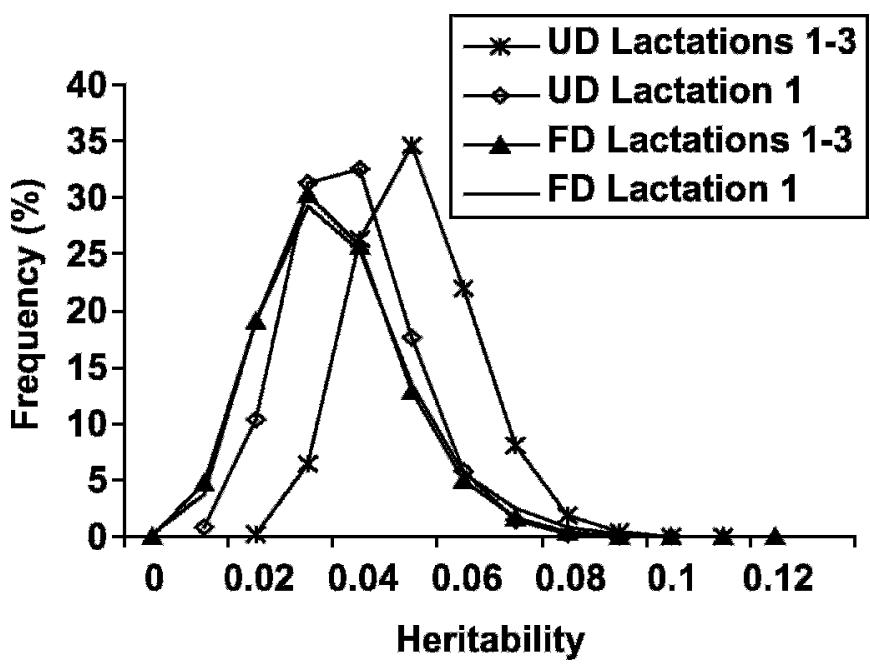

Figure 3. Posterior distributions of heritabilities of liability to udder diseases (UD), fertility diseases (FD), metabolic diseases (MD), and claw and leg diseases (CLD) for the first lactation and all lactations ( 1 to 3 ) estimated with the block model.

EBV ranged from -11 to 16 and from -19 to 15 , respectively. The EBV for PEY for lactation 1 only and lactations 1 to 3 were in the range of $-1,882$ to 1,043 , and $-2,609$ to 1,188 , respectively. The slopes of daily breeding values during lactation for the best and worst sire for PMY in the first lactation are shown in Figure 4.

\section{Correlations}

The Pearson correlations of EBV of the persistency traits with EBV of the health traits, and the correspond-

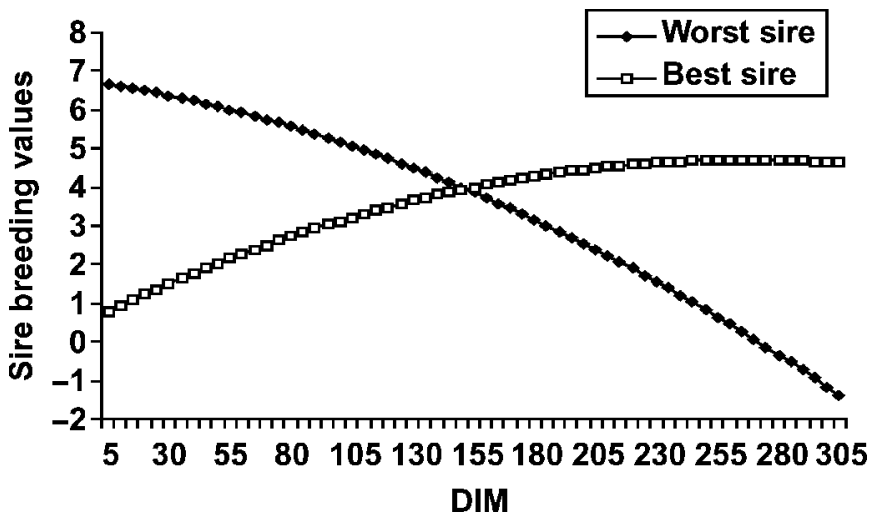

Figure 4. Estimated daily breeding values for the best and the worst bull for persistency of milk yield for the first lactation.

ing approximate genetic correlations are in Tables 5 and 6 for the lactation model and the block model, respectively. It bears repeating that the breeding values for the disease traits were multiplied by $(-1)$. For the first lactation, a highly significant $\left(\mathrm{P}_{\text {comparison-wise }}=\right.$ 0.006) Pearson correlation (genetic correlation) between PMY and CLD of 0.27 (0.46) was estimated using the lactation model, whereas a significant $\left(\mathrm{P}_{\text {comparison- }}\right.$ wise $=0.05)$ Pearson correlation of 0.19 and an approximate genetic correlation of 0.32 were found for PFY with CLD. In addition, a significant $\left(\mathrm{P}_{\text {comparison-wise }}=\right.$ 0.02) Pearson correlation between PEY and CLD of 0.23 (approximate genetic correlation of 0.38 ) was estimated. For the all-lactation data set and the lactation model, significant $\left(\mathrm{P}_{\text {comparison-wise }}=0.01\right.$ to 0.07$)$ Pearson

Table 4. Sire posterior mean (SPM) for daughters' probability of udder disease (UD), fertility disease (FD), metabolic disease (MD), and claw and leg disease (CLD) ${ }^{1}$

\begin{tabular}{lllll}
\hline & \multicolumn{3}{c}{ Disease } \\
\cline { 2 - 5 } & UD & FD & MD & CLD \\
\hline Model 1, data set 1 & & & & \\
Mean SPM for probability of disease (all sires) & 0.408 & 0.567 & 0.079 & 0.109 \\
SPM for probability of disease (best 10 sires) & 0.342 & 0.514 & 0.059 & 0.087 \\
SPM for probability of disease (worst 10 sires) & 0.473 & 0.625 & 0.118 & 0.129 \\
Model 1, data set 2 & & & 0.137 & 0.117 \\
Mean SPM for probability of disease (all sires) & 0.428 & 0.513 & 0.088 & 0.096 \\
SPM for probability of disease (best 10 sires) & 0.349 & 0.469 & 0.173 & 0.137 \\
SPM for probability of disease (worst 10 sires) & 0.513 & 0.561 & & - \\
Model 2, data set 1 & & & - & - \\
Mean SPM for probability of disease (all sires) & 0.149 & 0.187 & - & - \\
SPM for probability of disease (best 10 sires) & 0.118 & 0.162 & - & - \\
SPM for probability of disease (worst 10 sires) & 0.183 & 0.218 & & - \\
Model 2, data set 2 & & & - \\
$\quad$ Mean SPM for probability of disease (all sires) & 0.165 & 0.186 & - & - \\
SPM for probability of disease (best 10 sires) & 0.124 & 0.154 & - & - \\
SPM for probability of disease (worst 10 sires) & 0.208 & 0.222 & - & - \\
\hline
\end{tabular}

${ }^{1}$ Data for the first lactation (data set 1 ) and for all lactations (data set 2) were estimated with the lactation model (model 1) and with the block model (model 2) where each lactation was divided into 50-d periods and disease was scored as present or absent in each period. 
Table 5. Pearson correlations $\left(\mathrm{r}_{\mathrm{EBV}}\right)$ between estimated breeding values from the first lactation and all lactations for persistency of milk yield (PMY), persistency of fat yield (PFY), persistency of protein yield (PPY), persistency of milk energy yield (PEY) and liability to udder disease (UD), fertility disease (FD), metabolic disease (MD), and claw and leg disease (CLD) and the corresponding approximate genetic correlations $\left(\mathrm{r}_{\mathrm{g}}\right)^{1,2}$

\begin{tabular}{|c|c|c|c|c|c|c|c|c|}
\hline \multirow[b]{2}{*}{ Disease } & \multicolumn{2}{|l|}{ PMY } & \multicolumn{2}{|l|}{ PFY } & \multicolumn{2}{|l|}{ PPY } & \multicolumn{2}{|l|}{ PEY } \\
\hline & $r_{\mathrm{EBV}}$ & $r_{g}$ & $r_{\mathrm{EBV}}$ & $r_{g}$ & $\mathrm{r}_{\mathrm{EBV}}$ & $r_{g}$ & $\mathrm{r}_{\mathrm{EBV}}$ & $r_{g}$ \\
\hline \multicolumn{9}{|c|}{ First lactation } \\
\hline UD & $0.02(0.87)$ & 0.03 & $0.05(0.62)$ & 0.07 & $-0.11(0.27)$ & -0.17 & $0.02(0.86)$ & 0.03 \\
\hline FD & $0.15(0.14)$ & 0.23 & $0.13(0.20)$ & 0.20 & $0.09(0.38)$ & 0.14 & $0.15(0.13)$ & 0.24 \\
\hline $\mathrm{MD}$ & $0.06(0.53)$ & 0.10 & $0.11(0.27)$ & 0.17 & $0.10(0.34)$ & 0.15 & $0.12(0.24)$ & 0.19 \\
\hline CLD & $0.27(0.006)$ & 0.46 & $0.19(0.05)$ & 0.32 & $0.08(0.44)$ & 0.13 & $0.23(0.02)$ & 0.38 \\
\hline \multicolumn{9}{|c|}{ All lactations } \\
\hline UD & $-0.03(0.72)$ & -0.04 & $0.02(0.83)$ & 0.03 & $-0.06(0.45)$ & -0.07 & $-0.01(0.88)$ & -0.02 \\
\hline FD & $0.15(0.07)$ & 0.20 & $0.04(0.62)$ & 0.05 & $0.06(0.46)$ & 0.08 & $0.08(0.36)$ & 0.13 \\
\hline MD & $-0.15(0.07)$ & -0.19 & $-0.13(0.14)$ & -0.17 & $-0.12(0.17)$ & -0.15 & $-0.14(0.10)$ & -0.22 \\
\hline CLD & $0.21(0.01)$ & 0.32 & $0.13(0.10)$ & 0.20 & $0.11(0.19)$ & 0.17 & $0.16(0.05)$ & 0.27 \\
\hline
\end{tabular}

${ }^{1}$ Comparison-wise error probabilities are given in parentheses. In this lactation model, disease was scored as present or absent during the lactation.

${ }^{2}$ Approximate genetic correlations calculated according to Calo et al. (1973).

correlations were estimated for PMY with FD, MD, and CLD to be in the range of -0.15 to 0.21 .

\section{DISCUSSION}

\section{Disease Incidence}

Different data recording methods, data sources and disease definitions make comparison of disease frequencies across different studies difficult. In this study, the incidence rates per lactation of the different disease categories were higher than those reported by Zwald et al. (2004a), considering the diseases separately.

The distribution of incidences of UD across the 6 intervals was similar to that presented by Zwald et al. (2004a). These authors observed slightly more cases of mastitis in early lactation with an even distribution of mastitis throughout lactation. The presented incidences of FD for were higher than those reported by
Sander Nielsen et al. (1999), who reported frequencies for reproductive disorders for Danish Holsteins in the range of 11 to $15 \%$ for the first 3 lactations. The distribution of incidences of FD throughout lactation (Table 2) was in agreement with those reported by Zwald et al. (2004a) for cystic diseases. The incidence of CLD (Table 1) was higher than that reported by Sander Nielsen et al. (1999).

\section{Heritability of Disease Traits}

For the inference drawn from the estimated variance components, the respective standard errors should be considered. These are, in some cases, substantial compared with the respective mean of the sire variance (Table 3). Estimated heritabilities of liability to UD in both data sets (0.08) correspond well to estimates from threshold model analyses of clinical mastitis treated as

Table 6. Pearson correlations $\left(\mathrm{r}_{\mathrm{EBV}}\right)$ between estimated breeding values from the first lactation and all lactations for persistency of milk yield (PMY), persistency of fat yield (PFY), persistency of protein yield (PPY), persistency of milk energy yield and liability to udder disease (UD), and fertility disease (FD) and the corresponding approximate genetic correlations $\left(\mathrm{r}_{\mathrm{g}}\right)^{1,2}$

\begin{tabular}{|c|c|c|c|c|c|c|c|c|}
\hline \multirow[b]{2}{*}{ Disease } & \multicolumn{2}{|c|}{ PMY } & \multicolumn{2}{|l|}{ PFY } & \multicolumn{2}{|l|}{ PPY } & \multicolumn{2}{|l|}{$\mathrm{PEY}$} \\
\hline & $r_{\text {EBV }}$ & $r_{g}$ & $\mathrm{r}_{\mathrm{EBV}}$ & $r_{g}$ & $r_{\mathrm{EBV}}$ & $r_{g}$ & $r_{\mathrm{EBV}}$ & $r_{g}$ \\
\hline \multicolumn{9}{|c|}{ First lactation } \\
\hline UD & $0.01(0.90)$ & 0.01 & $0.05(0.60)$ & 0.06 & $-0.07(0.47)$ & -0.09 & $0.03(0.79)$ & 0.05 \\
\hline FD & $0.15(0.10)$ & 0.19 & $0.15(0.13)$ & 0.19 & $0.01(0.89)$ & 0.02 & $0.15(0.14)$ & 0.24 \\
\hline \multicolumn{9}{|c|}{ All lactations } \\
\hline UD & $-0.03(0.75)$ & -0.04 & $0.08(0.34)$ & 0.10 & $-0.02(0.85)$ & -0.02 & $0.04(0.67)$ & 0.06 \\
\hline FD & $0.12(0.10)$ & 0.15 & $0.005(0.95)$ & 0.006 & $0.02(0.78)$ & 0.03 & $0.04(0.63)$ & 0.06 \\
\hline
\end{tabular}

${ }^{1}$ Comparison-wise error probabilities are given in parentheses. In this block model, each lactation was divided into 50-d periods and disease was scored as present or absent in each period.

${ }^{2}$ Approximate genetic correlations calculated according to Calo et al. (1973). 
single binary trait, which ranged from 0.06 to 0.12 (Lund et al., 1999; Hinrichs et al., 2005). Hinrichs et al. (2005) estimated heritabilities for mastitis in a subset of the data used in this study applying a lactation threshold animal model. The results of these authors agreed with those presented in this study. Similar heritabilities of UD in the first lactation and in all lactations agreed with Sander Nielsen et al. (1999), whereas Heringstad et al. (2005) estimated a slightly higher heritability in the first lactation than in second and third lactations using a multitrait threshold model. The estimated heritability of FD in the first lactation was almost twice as large as in all lactations. This was in good agreement with estimates of Zwald et al. (2004a). These authors estimated heritabilities of 0.08 and 0.05 for cystic ovaries in first lactation and all lactations, respectively, using a threshold model, whereas estimates from linear model analysis by Van Dorp et al. (1998) for first-lactation cows were lower then those presented in this study. Estimated heritabilities for MD in the present study agreed with heritabilities of liability to ketosis and milk fever from threshold models, which ranged between 0.06 and 0.16 (Zwald et al., 2004a; Heringstad et al., 2005). The higher heritabilities for MD in the first lactation compared with all lactations were in line with estimated heritabilities of Zwald et al. (2004a) for ketosis. As for FD and MD, the heritability for CLD was higher for first lactation than for all lactations. A possible reason for the higher heritabilities in lactation 1 for $\mathrm{FD}, \mathrm{MD}$, and CLD could be the higher variation resulting from selection in first lactation. Additionally, the discrepancy between the heritability estimates in the first and in all lactations might be due to the trait definitions.

The block model (Eq. 2) is a repeatability model, which means that FD, as well as UD, were regarded as repeated measurements of the same trait in all blocks, respectively. For both data sets and trait categories, the posterior distributions of heritability were sharper when using the block model for the evaluation (Figure 3 ), illustrating the gain in precision from accounting for repeated measurements on the same animal in one lactation although correlation between the intervals may be not high enough for a repeatability model. Heringstad et al. (2004) estimated genetic correlations among 12 intervals of 3 lactations for mastitis to be in the range of 0.24 to 0.73 , using a multiple-trait longitudinal model. Lund et al. (1999) found strong genetic correlations of around 0.80 among clinical mastitis in early lactation ( -10 to $50 \mathrm{~d}$ after calving) and also in the periods 50 to $180 \mathrm{~d}$, and 181 to $350 \mathrm{~d}$ after first calving. In our block model, UD and FD were assumed the same trait in all blocks and lactations. This might be problematic, because both trait categories include several diseases, with different incidence rates in different stages of lactation and in different lactations, respectively. Unfortunately, it was not possible to analyze several diseases separately because the frequencies of single diseases in most blocks were too small.

Similar to the block models the lactation model for the all lactation data set is a repeatability model. This implies that the different disease categories were the same traits in all lactations. This might be problematic especially for $\mathrm{MD}$, because for this disease category the disease frequency increases with increasing lactation number, indicating that MD might not be the same trait in all lactations. The increasing disease frequency is mainly due to milk fever, which occurs more often in later lactations.

Table 4 shows that there are substantial genetic differences between sires with respect to their daughters' liability to the different disease categories. In general, the estimated sire posterior means for the daughters' probability to the respective disease were higher than those estimated by Zwald et al. (2004b), which is because of higher incidence rates presented in this study.

In a preliminary investigation, different formulas for the calculations of persistency of lactation used in Canada, Finland (Kistemaker, 2003), in the Netherlands (De Roos et al., 2001), and in Germany (www.lfl.bayern.de) were analyzed. A comparison showed strong correlations (>0.90) among them. This was in accordance with results presented by Kistemaker (2003). The range of the persistency proofs showed that persistency in first lactation is probably not the same trait as in later lactations. This corresponds to results presented by Kistemaker (2003), who estimated correlations between first and second lactations and between second and third lactations of 0.54 and 0.69 , respectively.

\section{Correlations Between Disease Traits and Lactation Persistency Traits}

During this study approximate genetic correlations were obtained by performing a univariate evaluation and using the formula provided by Calo et al. (1973). The comparison of this approach with the results of a bivariate analysis would provide insights into the accuracy of the formula of Calo et al. (1973) in our study. However, such a comparison would go beyond the aim of this study.

From an immunological point of view, Capuco et al. (2003) showed that epithelial cells provide a means to regulate mammary cell proliferation and thus to enhance persistency, whereas mastitis increased death of mammary cells. Accordingly, Capuco et al. (2003) argued that persistency and mastitis influence each other negatively. This coherence was not affirmed by the pres- 
ent study, because correlations between UD and persistency measures were close to zero.

The approximate genetic correlations between FD and the different persistency traits were not always significant for both models and data sets (Tables 5 and 6 ), indicating a loose relationship among them. Muir et al. (2004) estimated genetic correlations between PMY and nonreturn rate at $56 \mathrm{~d}$ after insemination for first and later lactations, of 0.16 and 0.32 , respectively. Haile-Mariam et al. (2003) reported a very loose genetic relationship between PMY and calving interval of 0.02 . In contrast, Bar-Anan et al. (1985) estimated a strong relationship based on correlations between EBV for conception rate and PMY of 0.42 .

The estimated negative correlations between MD and different persistency traits indicate that cows having metabolic diseases tended to have more persistent lactations or that cows that had fewer metabolic diseases tended to have less-persistent lactations. The majority of MD occurred during the first $50 \mathrm{~d}$ of lactation. Diseased cows tend to have lower yields on $d 60$, and the peak yield was at a later stage of lactation (not shown), possibly causing the antagonistic relationship between MD and persistency of lactation. This is in agreement with Muir et al. (2004). These authors estimated genetic correlations between calving difficulty and day in milk at the peak milk yield of 0.15 , indicating that cows with difficult calving tended to have a later peak. The strongest approximate genetic correlation was found between PMY and CLD for first lactation (Table 5). Even the stringent experimental error probability appeared to be significant $\left(\mathrm{P}_{\text {experiment-wise }}=0.09\right)$. In addition, all persistency traits except PPY had positive, significant correlations with CLD in both data sets (Tables 5 and 6). The positive genetic correlations indicate that a persistent cow has a lower liability for claw and leg diseases. Alternatively, one could argue that a lower liability for claw and leg diseases leads to more persistent lactations. In contrast to $\mathrm{MD}, \mathrm{CLD}$ were more evenly distributed throughout lactation, indicating the continuous impact of CLD on the daily milk yield throughout lactation. Therefore, the impact of CLD on the height of the milk yield on d 60 was much lower than for MD (not shown).

To further investigate the impact of the negative energy balance at the beginning of the lactation on the liability to the diseases, the approximate genetic correlations between PEY and the 4 health traits were analyzed in addition to PMY, PFY, and PPY. The significant correlations between PEY and CLD as well as MD (Table 5) indicate that the energy balance has an impact on the liability of different disease traits. This was also reported by Muir et al. (2004), who speculated that persistency could be genetically correlated with less severe early lactation energy balance. In addition, the assertion is strengthened by Ferris et al. (1985); these authors argued that persistency appears to be positively correlated with late peak and lower peak yield. Both are indicators of less negative energy balance. In addition, the negative energy balance is presumed to cause a higher liability to diseases. Knight et al. (1999) argued that metabolic stress is caused by more synthesis and secretion of milk at the beginning of lactation, thus leading to a negative energy balance. Furthermore, Knight et al. (1999) claimed that the synthesis and secretion of milk causes a negative energy balance, in such a way that some energetic processes, including those that maintain general health, have to be downregulated.

The approximate genetic correlations between the persistency traits and the health traits have to be judged in the light of the definition of persistency. In the present study the definition of persistency of lactation does not account for the level of production, although this might be of importance when analyzing the association between the shape of production throughout lactation and metabolic stress. Besides, the level of production at the peak yield might be a relevant parameter to study the influence of the shape of the lactation on the susceptibility to different diseases. Jakobsen et al. (2003) estimated genetic correlations between disease liability and milk yield on $\mathrm{d} 85$ to be in the range of 0.40 to 0.52 , which indicates that the peak yield might have higher genetic correlations with diseases than does persistency itself. However, this assumption could not be confirmed in the present study.

\section{CONCLUSIONS}

Estimated heritability of liability to UD, FD, MD, and CLD ranged from 0.04 to 0.12 . Significant differences among sires with respect to their daughters' liability to the different disease categories were found, indicating that there is scope for genetic improvement of the traits. The introductory hypothesis was that good persistency leads to fewer health problems, based on less metabolic stress at the beginning of lactation. This was partly affirmed by the significant positive correlations of PMY, PFY, and PEY with CLD. In contrast, the negative approximate genetic correlations between persistency measures and MD as well as the loose relationships of persistency traits with UD and FD refute the thesis. Based on the results of the present study, it seems doubtful that the inclusion of persistency in the breeding goal would lead to a genetic improvement in the disease traits. This is especially true when one considers that the genetic correlation between persistency and the different disease traits showed different signs. 


\section{ACKNOWLEDGMENTS}

This manuscript has benefited from critical and helpful comments of 2 anonymous reviewers.

\section{REFERENCES}

Bar-Anan, R., M. Ron, and G. R. Wiggans. 1985. Associations among milk yield, yield persistency, conception and culling of Israeli Holstein dairy cattle. J. Dairy Sci. 68:382-386.

Calo, L. L., R. E. McDowell, L. D. VanVleck, and P. D. Miller. 1973. Genetic aspects of beef production among Holstein-Friesians pedigree selected for milk production. J. Anim. Sci. 37:676-682.

Capuco, A. V., S. E. Ellis, S. A. Hale, E. Long, R. A. Erdman, X. Zhao, and M. J. Paape. 2003. Lactation persistency: Insights from mammary cell proliferation studies. J. Anim. Sci. 81(Suppl. 3): $18-31$.

De Roos, A. P. W., A. G. F. Harbers, and G. de Jong. 2001. Random regression test-day model in The Netherlands. Interbull Bull. 27:155-158.

Dekkers, J. C. M., J. H. Ten Hag, and A. Weersink. 1998. Economic aspects of persistency of lactation in dairy cattle. Livest. Prod. Sci. 53:237-252.

Ferris, T. A., I. L. Mao, and C. R. Anderson. 1985. Selection for lactation curve and milk yield in cattle. J. Dairy Sci. 68:14381448.

Geyer, C. 1992. Practical Markov chain Monte Carlo. Stat. Sci. $7: 473-511$.

Gianola, D. 1982. Theory and analysis of threshold characters. J. Anim. Sci. 54:1079-1096.

Gianola, D., and J. L. Foulley. 1983. Sire evaluation for ordered categorical data with a threshold model. Genet. Sel. Evol. 15:201-224.

Grossman, M., S. M. Hartz, and W. J. Koops. 1999. Persistency of lactation yield: A novel approach. J. Dairy Sci. 82:2192-2197.

Haile-Mariam, M., P. J. Bowman, and M. E. Goddard. 2003. Genetic and environmental relationship among calving interval, survival, persistency of milk yield and somatic cell count in dairy cattle. Livest. Prod. Sci. 80:189-200.

Heringstad, B., Y. M. Chang, D. Gianola, and G. Klemetsdal. 2004. Multivariate threshold model analysis of clinical mastitis in multiparous Norwegian dairy cattle. J. Dairy Sci. 87:3038-3046.

Heringstad, B., Y. M. Chang, D. Gianola, and G. Klemetsdal. 2005. Genetic analysis of clinical mastitis, milk fever, ketosis, and retained placenta in three lactations of Norwegian Red cows. J. Dairy Sci. 88:3273-3281.

Hinrichs, D., E. Stamer, W. Junge, and E. Kalm. 2005. Genetic analyses of mastitis data using animal threshold models and genetic correlation with production traits. J. Dairy Sci. 88:2260-2268.

Jakobsen, J. H., R. Rekaya, J. Jensen, D. A. Sorensen, P. Madsen, D. Gianola, L. G. Christensen, and J. Pedersen. 2003. Bayesian estimates of covariance components between lactation curve parameters and disease liability in Danish Holstein cows. J. Dairy Sci. 86:3000-3007.
Jamrozik, J., G. Jansen, L. R. Schaeffer, and Z. Liu. 1998. Analysis of persistency of lactation calculated from a random regression test day model. Interbull Bull. 17:64-69.

Kirkpatrick, M., D. Lofsvold, and M. Bulmer. 1990. Analysis of the inheritance, selection and evolution of growth trajectories. Genetics 124:979-993.

Kistemaker, G. J. 2003. Comparison of persistency definitions in random regression test-day models. Interbull Bull. 30:96-98.

Knight, C. H., D. E. Beever, and A. Sorensen. 1999. Metabolic loads to be expected from different genotypes under different systems. Metabolic stress in dairy cows. Br. Soc. Anim. Sci. Occ. Publ. No. 24:27-36.

Krogmeier, D. 2003. Der Ökologische Gesamtzuchtwert für Fleckvieh, Braunvieh und Gelbvieh. Beitrag zur Konferenz Forschung für den ökologischen Landbau in Bayern. Schrift. Bayern. Landes. Landwirtsch. 3:77-86.

Liu, Z., F. Reinhardt, and R. Reents. 2000. Estimating parameters of a random regression test day model for first three lactation milk production traits using the covariance function approach. Interbull Bull. 25:74-80.

Lund, M. S., J. Jensen, and P. H. Petersen. 1999. Estimation of genetic and phenotypic parameters for clinical mastitis, somatic cell production deviance, and protein yield in dairy cattle using Gibbs sampling. J. Dairy Sci. 82:1045-1051.

Lyons, D. T., A. E. Freeman, and A. L. Kuck. 1991. Genetics of health traits in Holstein cattle. J. Dairy Sci. 74:1092-1100.

Muir, B. L., J. Fatehi, and L. R. Schaeffer. 2004. Genetic relationships between persistency and reproductive performance in first-lactation Canadian Holsteins. J. Dairy Sci. 87:3029-3037.

Nostitz, B., and H. Mielke. 1995. Vergleich verschiedener Methoden der Bestimmung des Milchenergiegehaltes beim Schwarzbunten Milchrind. J. Anim. Physiol. A. Anim. Nutr. 73:9-18.

Reinsch, N. 1996. Two Fortran programs for the Gibbs Sampler in univariate linear mixed models. Arch. Tierzucht. 39:203-209.

Sander Nielsen, U., G. A. Pedersen, J. Pedersen, and J. Jensen. 1999. Genetic variation in disease traits and their relationships with survival in Danish dairy cattle. Interbull Bull. 21:170-177.

Sorensen, D., S. Andersen, D. Gianola, and I. Korsgaard. 1995. Bayesian inference in threshold models using Gibbs sampling. Genet. Sel. Evol. 27:229-249.

Tamminga, S. 2000. Issues arising from genetic change: Ruminants. The Challenge of Genetic Change in Animal Production. W. G. Hill, S. C. Bishop, B. McGuirk, J. C. McKay, G. Simm, and A. J. Webb, ed. Br. Soc. Anim. Sci. Occ. Publ. No. 27:55-62.

Van Dorp, T. E., J. C. M. Dekkers, S. W. Martin, and J. P. T. M. Noordhuizen. 1998. Genetic parameters of health disorders, and relationships with 305-day milk yield and conformation traits of registered Holstein cows. J. Dairy Sci. 81:2264-2270.

Zwald, N. R., K. A. Weigel, Y. M. Chang, R. D. Welper, and J. S. Clay. 2004a. Genetic selection for health traits using producerrecorded data. I. Incidence rates, heritability estimates, and sire breeding values. J. Dairy Sci. 87:4287-4294.

Zwald, N. R., K. A. Weigel, Y. M. Chang, R. D. Welper, and J. S. Clay. 2004b. Genetic selection for health traits using producerrecorded data. II. Genetic correlations, disease probabilities, and relationships with existing traits. J. Dairy Sci. 87:4295-4302. 